\title{
An application of seismic attributes analysis for mapping of gas bearing sand zones in the sawan gas field, Pakistan
}

\author{
Tahir Azeem $^{1}$ (D) Wang Yanchun ${ }^{1} \cdot$ Perveiz Khalid $^{2} \cdot$ \\ Liu Xueqing ${ }^{1} \cdot$ Fang Yuan $^{1} \cdot$ Cheng Lifang $^{1}$
}

Received: 3 April 2015/Accepted: 7 December 2015/Published online: 21 December 2015

(C) Akadémiai Kiadó 2015

\begin{abstract}
Sandstone intervals of the Lower Goru Formation of the Cretaceous age are proven reservoir intervals in the middle Indus Basin, Pakistan. However, based on seismic data interpretation, it is difficult to differentiate payable gas sand from non-payable gas sand. Various types of post-stacks seismic attributes are extracted and analyzed to differentiate payable gas sand from non-payable. The analysis reveals that average instantaneous frequency, peak spectral frequency, average instantaneous phase and sweetness seem to be more effective attributes along with energy half time. Sweetness attribute map shows two sweet spot below the targeted window which indicate to the presence of gas play. Statistical analysis is also carried out to find the associations between seismic attributes and thickness of gas layer values. Cross plots of these attributes were quantified through regression analysis. A good correlation with regression coefficient $\left(R^{2}\right)>0.78$ is found between seismic attributes and gas layer thickness except average instantaneous phase attribute, which lays the foundation for predicting the thickness of gas reservoir.
\end{abstract}

Keywords Post-stack attributes - Statistical analysis - Sawan gas field · Gas layer thickness · Gas bearing sand zones

\section{Introduction}

Discrimination of hydrocarbon sand intervals from non-hydrocarbon sands can easily possible from the interpretation of seismic data (Dobrin and Savit 1988; El-Mowafy and Marfurt 2008; Khalid et al. 2014a). However, it is difficult to distinguish payable hydrocarbon interval from non-payable interval by the interpretation of seismic data only

Tahir Azeem

tahir2rd@yahoo.com

1 China University of Geosciences, Beijing 100083, China

2 Institute of Geology, University of the Punjab, Lahore 54590, Pakistan 
(Khalid and Ghazi 2013). For this purpose, various techniques and methods are in practice (Marfurt et al. 1998; Fu et al. 2006; Khalid et al. 2014b). The sand intervals of the Lower Goru Formation of the Cretaceous age are producing oil and gas in various parts of Lower, Middle and Upper Indus basin of Pakistan. However, in Swan gas field $\left(26.80^{\circ}-27.40^{\circ} \mathrm{N}\right.$, $68.70^{\circ}-69.40^{\circ} \mathrm{E}$ ) in the Middle Indus basin, several wells drilled in these sand intervals, declared dry or abandoned. These wells were drilled in these intervals based on structural interpretation of seismic data. However, based on this qualitative interpretation, we were unable to differentiate between payable and non-payable sand intervals. The quantitative analysis of seismic amplitude anomalies was not considered. In this work, an attempt is made to resolve seismic amplitudes related problems through seismic attribute analysis as suggested by Taner et al. (1979).

Among various seismic techniques, seismic attributes is a powerful tool, which can be utilized to interpret pore fluid saturation and type at in situ conditions (Marfurt et al. 1998). According to application various researchers have been classified the seismic attributes into different categories. Taner et al. (1994) has divided seismic attributes into geometrical and physical attributes. Physical attributes are closely linked with lithology, change in depositional environments and pore fluid properties. These attributes are commonly used to predict the reservoir properties of the targeted interval (Bodine 1984, 1986; Taner 2001; Løseth et al. 2009; Raef et al. 2015). With the advent of digital recording the quality of seismic amplitude data has been tremendously improved (Chopra and Marfurt 2005). Seismic amplitude is used as principal parameter to determine the physical properties of rock-fluid composite, as the strong amplitudes (bright spots) have a good correlation with lithology, pore fluid properties and edges of hydrocarbon-water interfaces (Bodine 1984, 1986; Taner 2001; Chopra and Marfurt 2005). However, when the thickness of the reservoir interval is very close to seismic resolution limit then, the reflected signals from the top and bottom of the layers undergo constructive or destructive interference which, causes to produce a single event of high amplitude (Widess 1973; Robertson and Nogami 1984; Chung and Lawton 1995). Such kinds of events create ambiguity and make it difficult to distinguish the productive and non-productive sand through conventional amplitude analysis (Rana et al. 2006). Therefore, to improve the reservoir analysis, in addition to amplitude attributes other seismic attributes such as sweetness, average instantaneous phase, average instantaneous frequency and spectral frequency etc. are in practice (Horkowitz and Davis 1996; Taner 2001; Rana et al. 2006; Hart 2008; Ye et al. 2008; Raef et al. 2015). Sweetness is commonly used to identify the sand, shale, sandstones and channel sand and also helpful to check the lateral as well as vertical continuity of the targeted interval (Hart 2008; Ahmad and Rowell 2012; Wang et al. 2012). Post stack attributes like RMS amplitude, maximum peak amplitude, maximum trough amplitude, average instantaneous frequency, average instantaneous phase and relative impedance have good relation with the lateral variation of the reservoir, while reflection intensity, peak spectral frequency attributes are sensitive to reservoir thickness (Marfurt and Kirlin 2001; Taner 2001; Gholami et al. 2014).

2D post-stack seismic and wireline well log data has been used to complete this study. The base map of 2D seismic lines and location of wells are shown in Fig. 1. Synthetic seismogram of each well was developed, on the basis of seismic to well tie; target zone was marked on seismic sections. Horizon $\mathrm{D}_{1}$ and $\mathrm{C}_{1}$ were selected as top and bottom horizons to extract various types of post-stack seismic attributes as shown in Fig. 2. Time window value between these two horizons is $80 \mathrm{~ms}$ (mille seconds) at Sawan-07 well location. Contour maps of the extracted seismic attributes have been developed and analyzed to identify the gas bearing and non-gas bearing sand zones. To further investigate the area statistical analysis were carried out; statistical analysis also supports our interpretation. 


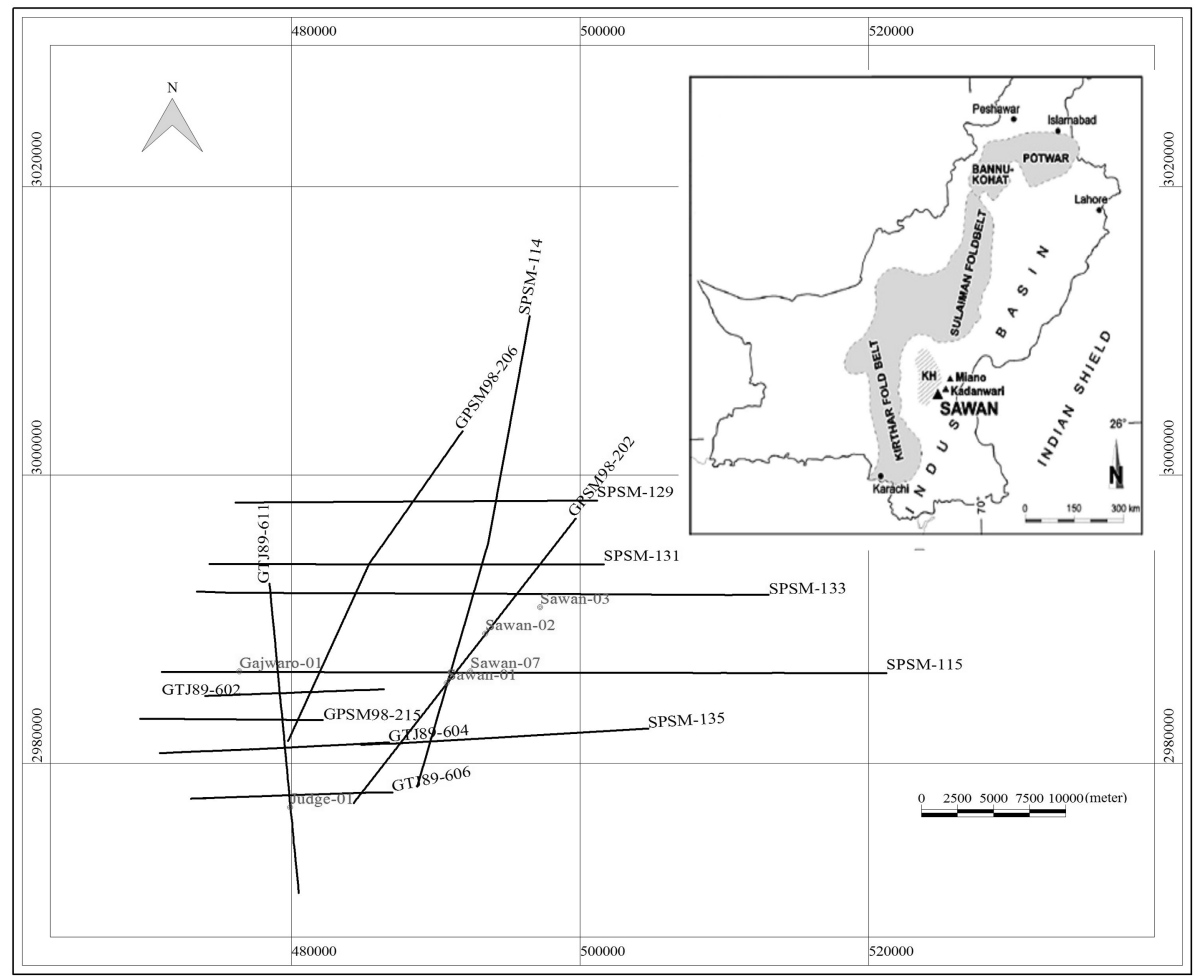

Fig. 1 (Inset) Location map of the study area. Base map of seismic lines and position of drilled wells in the study area

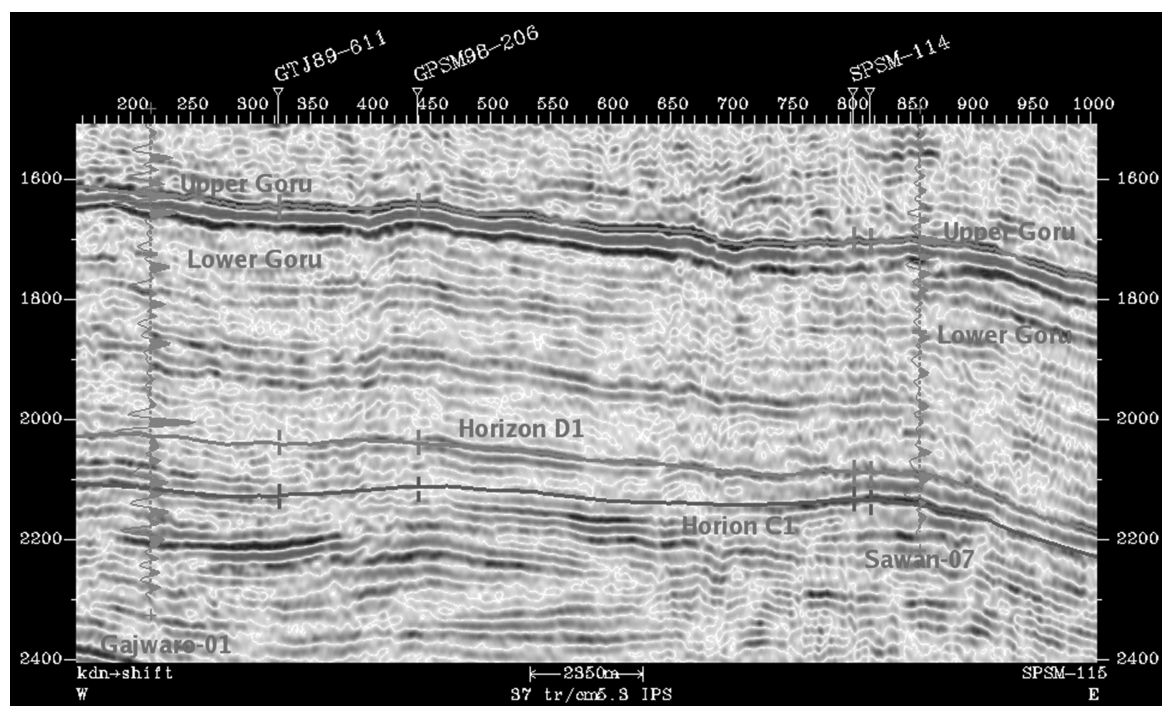

Fig. 2 Seismic to wells tie of Gajwaro-01 and Sawan-07 wells with seismic line SPSM-115 and position of horizons D1 and $\mathrm{C} 1$, which are used for attributes extraction 


\subsection{Geology of the area}

The study area is a part of the Middle Indus Basin, which is bounded by Sargodha High in the north, Jacobabad and Mari-Kandkot Highs (collectively called Sukkur Rift) in the south. The eastern boundary is marked by the Indian Shield and the western boundary is marked by Kirthar and Suleiman Fold and Thrust Belt (Kadri 1995). Structural configuration of this area is the direct result of three post-rifting tectonic events: late Cretaceous uplifting and erosion, basement rooted NW-SE oriented wrench faults and late Tertiary to recent uplifting of Jacobabad and Khairpur High (Ahmad et al. 2004). These Highs (Jacobabad and Khairpur) play an important role to form the structural and stratigraphic traps in the Kadanwari and Sawan areas (Ahmad et al. 2004; Berger et al. 2009). In the study area, the uplifting of Khairpur High positioned the Lower Goru sequence such as, reservoir quality sand of proximal depositional system are positioned into structurally deep areas whereas, nonreservoir quality distal parts are positioned updip to form the traps (Berger et al. 2009).

The organic rich black shales of Cretaceous ages are the proven source rock in the Middle and Lower Indus Basin which, are mainly composed of shale with subordinate amounts of black siltstone, sandstone and nodular argillaceous limestone (Kadri 1995). The Formation was deposited in the marine environments at the western passive margin of the Indian plate. Thickness of the Sembar Formation ranges from 0 to more than $260 \mathrm{~m}$ (Iqbal and Shah 1980). The Sembar Formation is deeply buried and thermally mature towards the western edge of the Indus basin and becomes shallower and less mature towards the eastern edge (Wandrey et al. 2004). The Sembar Formation is overlain by the Lower Goru Formation, which is the proven reservoir rock in the study area. The upper part of the Lower Goru is mainly composed of shale whereas the lower part is mainly composed of medium to coarse grained sandstones with thin layers of shale and limestone. The lower portion of this reservoir character sandstones is further divided into A, B, C and D sand intervals (Fig. 3) (Krois et al. 1998). Deposition of these reservoir intervals took place in deltaic, shallow marine environments during lowstand phase; when detached medium to coarse grained sediments were deposited on top of the distal (shale and siltstone) sediments of the previous highstand systems tract (Berger et al. 2009). Petrographically, A and B intervals can be classified as quartz arenites (Berger et al. 2009) whereas, C interval includes significant amount of partially altered volcanic rock fragments and pore lining iron chlorite cement due to which, the sands of this interval can be classified as sublith to lithic arenites (McPhee and Enzendorfer 2004; Berger et al. 2009). Sands of B and C intervals are the main reservoirs in the study area (Munir et al. 2011) and show high porosities (average absolute porosities $16 \%$ ) and permeabilities between the depths of 3000-3500 m. This reservoir interval of the Lower Goru Formation is directly overlain by transgressive shales and siltstones of the Upper Goru Formation, which act as regional seal in the Middle and Lower Indus basin (Berger et al. 2009).

\section{Methodology}

The proper identification of hydrocarbon bearing reservoir zones based on 2D seismic data analysis has always been a very challenging task. In the study area, the thickness of reservoir sandstone intervals at some places is very close to seismic resolution limit, which make it difficult to differentiate productive and non-productive reservoir intervals. In this study, we used wireline logs of six wells (Fig. 1), out of which four wells (Sawan-01, 
Fig. 3 Stratigraphic column representing the shale and sand intervals ( $A, B, C$ and $D$ sand intervals) of Lower Goru formation modified after Krois et al. (1998)

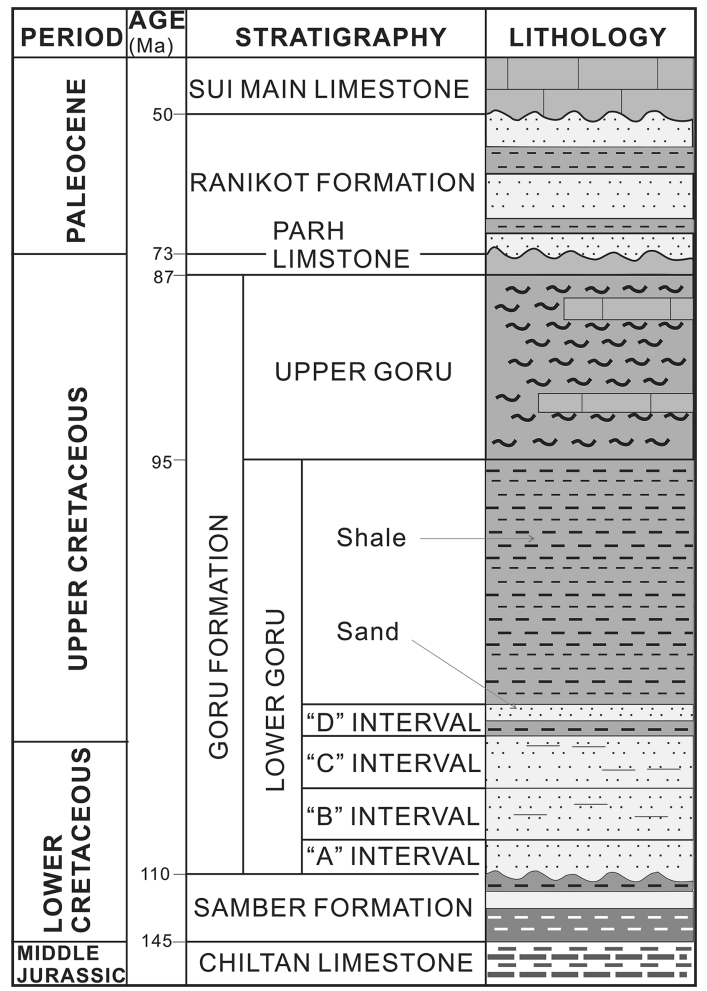

Sawan-02, Sawan-03 and Sawan-07) have been proven productive whereas, the other two wells (Gajwaro-01, Judge-01) are non-productive. Each well has a complete suite of wireline logs such as gamma ray, spontaneous potential, density, sonic and resistivity logs. The aim of this study is to minimize the risk of predicting non-productive wells by delineating gas bearing and non-gas bearing sand zones with the help of seismic attributes analysis. Statistical analysis also carried out to find the relationship between seismic attributes and petrophysical properties. These statistical relationships will be helpful to analyze the vertical and lateral variations in the reservoir interval. The workflow used in this study is shown in Fig. 4.

In first step, we developed synthetic seismograms by using well log and $2 \mathrm{D}$ seismic data which helped us to relate the well Formations tops with specific reflector on seismic sections. To find the targeted area on seismic sections, we analyzed the well logs data, on the basis of these analysis we were able to identify the reservoir zone. Well log analysis also proven helpful to estimate the thickness of gas reservoir. In next step we used 2D poststack seismic data to extract the various types of seismic attributes within the targeted interval. Contours map of each attribute has been generated and analyzed to delineate the gas bearing and non-gas bearing sand zones. To make the picture more clear trace based instantaneous seismic attribute such as sweetness was also extracted and analyzed. Combined analysis of these attributes has been proven helpful to identify the gas bearing and non-gas bearing zones as well as depositional environments. Finally, we performed regression analysis to quantify the correlation between seismic attributes and thickness of 


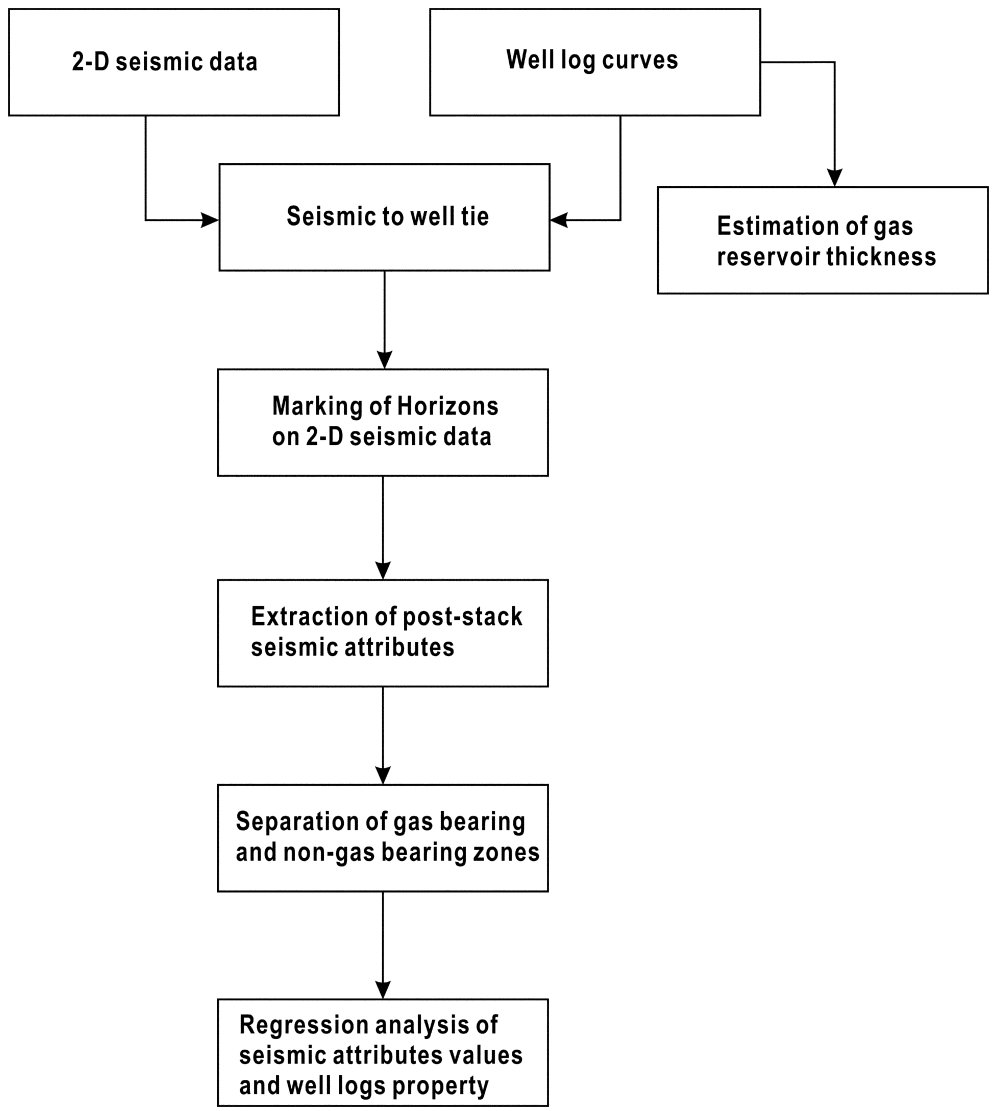

Fig. 4 Work flow used in this study to differentiate gas bearing sand from non-gas bearing sand intervals

gas reservoir. This regression results provide us useful physical basis relationships between seismic attributes and well log property.

\section{Results}

\subsection{Analysis of well data and seismic to well tie}

We marked the reservoirs zones by analyzing wells log data. Based on gamma ray, SP and density logs interpretation, major lithologies along with sand intervals are marked in Sawan-01 well as shown in Fig. 5. A large crossover between neutron and density logs in the selected zone is a classical signature for the presence of gas. Sharp variation in sonic log response (DT) and gap between resistivity curves (LLD and LLS logs) reading in the selected zone also support this argument. From well logs, it is clear that the thickness of this sand interval in Sawan-01 well is about 70 m. From Fig. 5 it is also clear that in the gas bearing zone the gamma ray log shows low value in Sawan-01, 03 and 07 wells whereas in Sawan-02 gamma ray shows comparatively high values, which mean that 

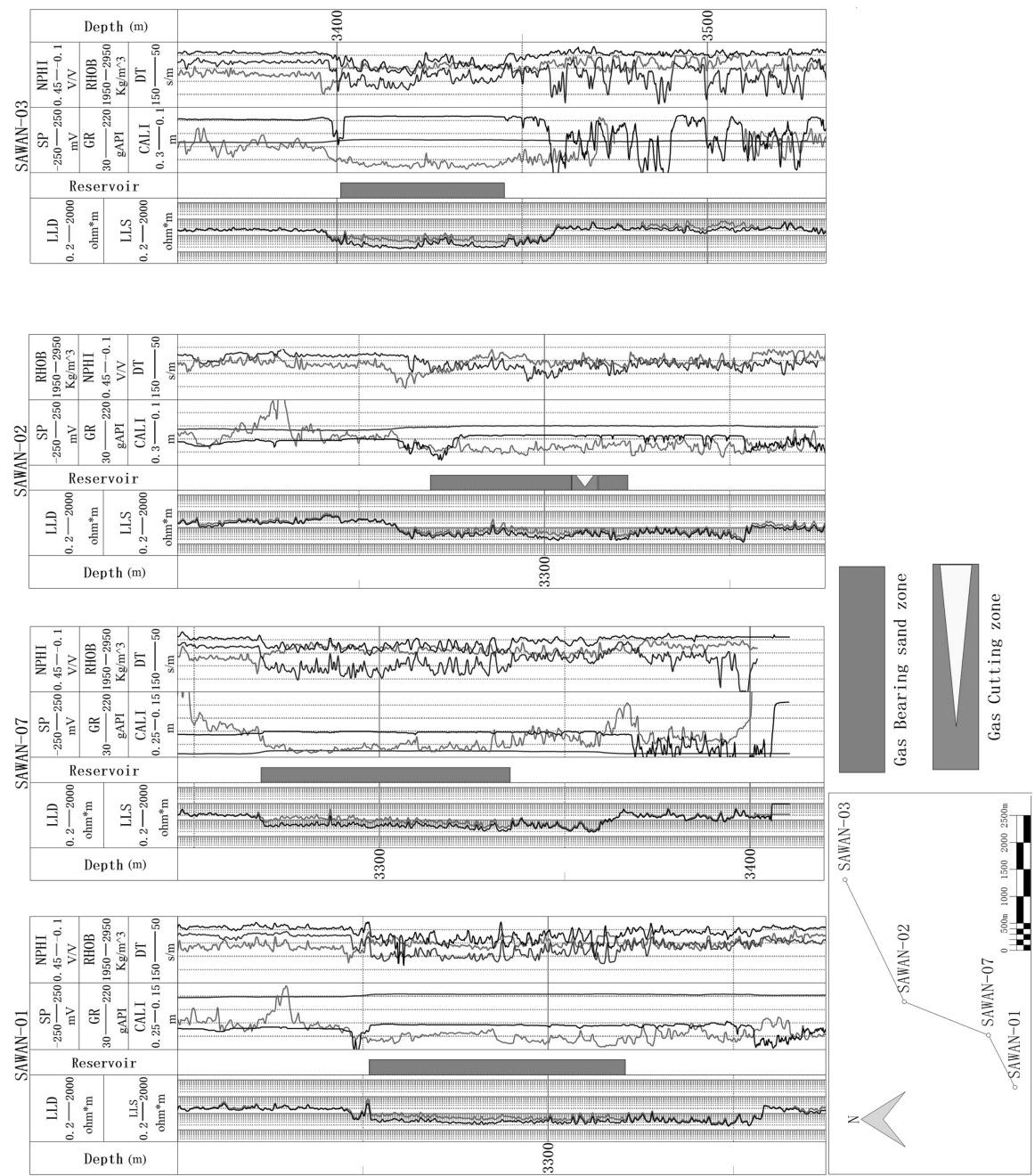

Fig. 5 Composite logs of Sawan-01, 02, 03 and 07 wells indicating the lateral and vertical variation of gas reservoir in Lower Goru formation

comparatively high percentage of shale is present in this reservoir zone. The presence of this shale also shows its effect on the thickness of gas reservoir as shown in Fig. 5. The thickness of gas sand intervals in other wells (Sawan-02, Sawan-03 and Sawan-07) is also calculated by using the above discussed well $\log$ analysis, which is 37,44 and $67 \mathrm{~m}$ respectively, whereas, Gajwaro-01 and Judge-01 wells have no signature of gas.

Seismic to well tie was performed to find a relation between time and depth domains, this time-depth relationship increase the accuracy and reliability of the work. Sonic and density logs provide information about the velocity and density of the subsurface layers respectively (Badly 1985). These $\operatorname{logs}$ (sonic and density) were used to generate the reflectivity series of the subsurface layers of the earth. This reflectivity series was 


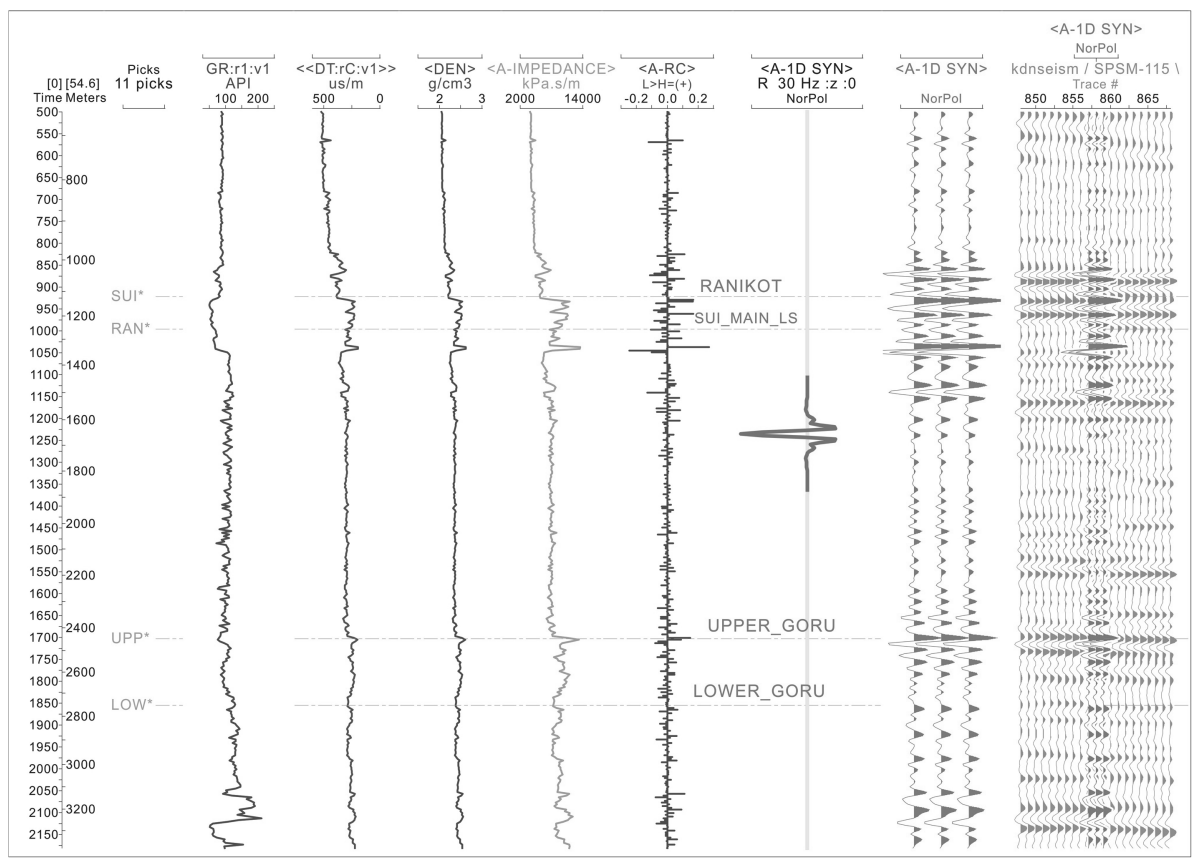

Fig. 6 Synthetic seismogram of Sawan-07 well with seismic line SPSM-115

convolved with the source wavelet (Ricker wavelet) to generate the synthetic seismograms. A Ricker wavelet of $30 \mathrm{~Hz}$ dominant frequency (extracted from seismic data) was used to generate synthetic seismogram. Based on these seismograms well formation tops were related with the specific reflection on the seismic sections as shown in Fig. 6. Figure 2 shows the seismic to well tie of Gajwaro-01 and Sawan-07 wells with seismic line SPSM115. This correlation helped us to mark the targeted horizons on seismic sections.

\subsection{Seismic attributes}

Seismic attributes are commonly used to delineate the seismic features of interest. We used standard (horizons and trace based) post-stack attributes to analyze the pore fluid characteristics of reservoir interval. Sonneland et al. (1989) introduced the interval attributes while Dalley et al. (1989) introduced the horizon based seismic attributes. These attributes are helpful to interpret the reflector characteristics, which cannot be easily observed on the seismic sections. In this study PostStack/PAL tool of Landmark software is used to extract a suite of post-stack seismic attributes from $2 \mathrm{D}$ seismic data. $\mathrm{D}_{1}$ and $\mathrm{C}_{1}$ horizons were used as top and bottom horizons to extract the horizon based seismic attributes. PostStack/PAL tool has ability to calculate the attribute values over the specified interval of interest, then outputs these results in the form of horizon data file. We used these outputs data files to construct the contours map of each attribute. The attributes used in this study are discussed below. 


\subsection{RMS amplitude}

RMS amplitude is directly linked with reservoir properties and startigraphic events. It can be calculated as the square root of the average of the energy sum found in the analysis time window. Mathematically it can be expressed as

$$
A_{\text {rms }}=\sqrt{\frac{1}{N} \sum_{i=1}^{N} A(i)^{2}}
$$

where $A_{r m s}$ is RMS amplitude, $N$ is number of samples and $A$ is amplitude of the sample. Equation (1) shows that attribute is very sensitive to high amplitudes values as during the extraction of this attribute amplitude values are squared before averaging. Figure 7 shows the contour map of RMS amplitude. Four moderate to high amplitude zones can be clearly seen on map. These moderate to high amplitude values are often associated with lithological changes, channel sand bodies, high porosity (porous sands), sand rich shoreward

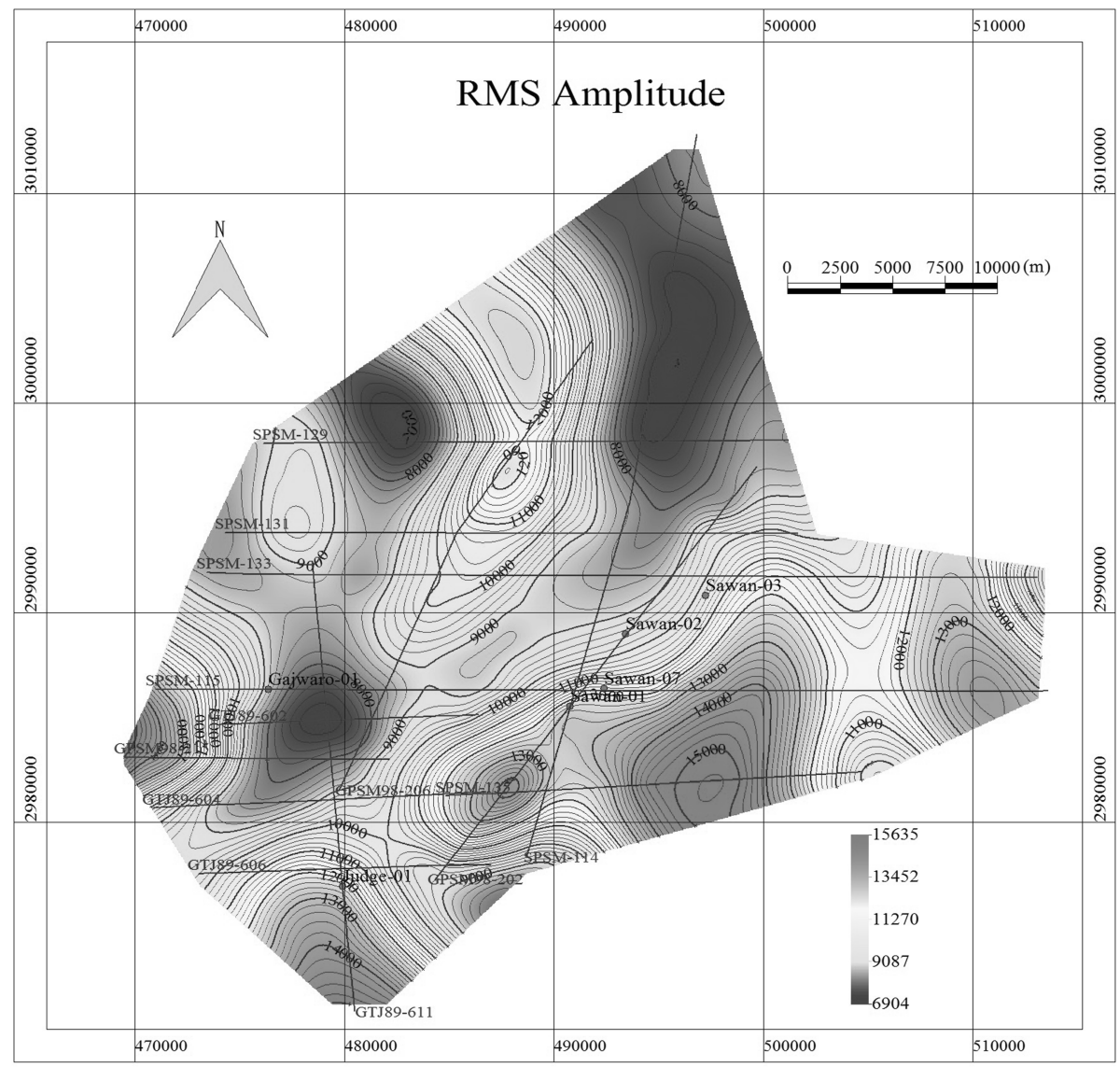

Fig. 7 RMS amplitude attribute map separates the low and high amplitude zones in Lower Goru Formation. Contour spacing between two consecutive lines is 200. (Color figure online) 
facies, bright spots and especially gas saturated sand zones (Taner et al. 1979; Yushuang and Simiao 2013). Whereas low amplitudes values may indicate that these zones contain sandyshale, pro-delta or abyssal plain facies and not favorable for gas potential.

\subsection{Maximum peak amplitude}

Maximum peak amplitude gets the maximum value between the time windows on seismic data. Attribute is suitable to measure the amplitude anomalies within sequences. The contours map of this attribute is shown in Fig. 8. Map clearly separates different geological features. Red color represent to higher amplitudes values, whereas blue color represent to low amplitudes values. Moderate to high amplitude values are the indication of gas sand accumulation in the respective zones. Gas bearing sand sediments exhibits low velocity and density as compared to surrounding water bearing sand or shale sediments, these low values causes to produce high negative reflection and for land areas wavelet also have negative sign as, in this case so, their convolution gives a high positive amplitude values. Often these high values have good correlation with porosity and hydrocarbon saturation of

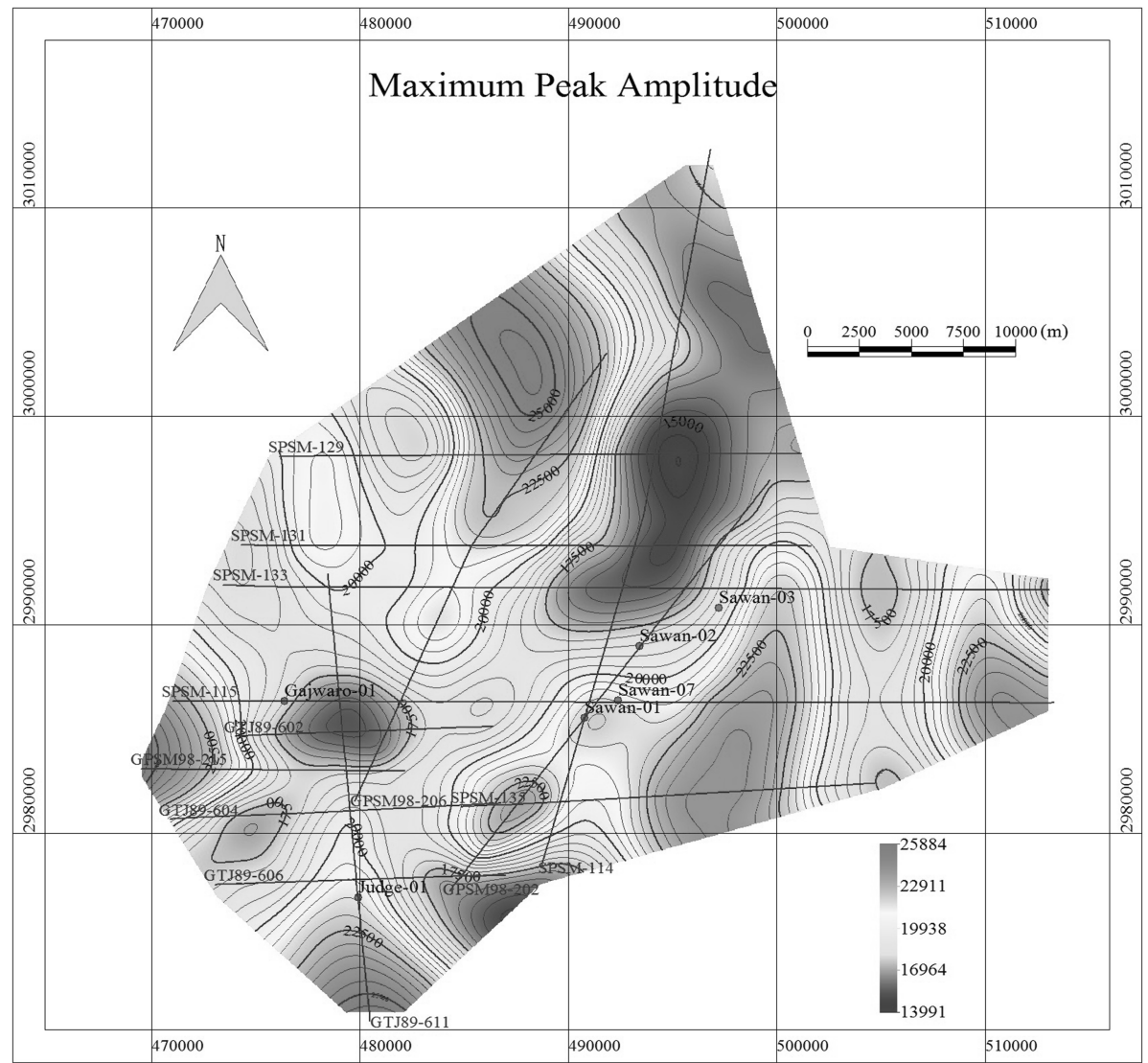

Fig. 8 Maximum peak amplitude attribute map clearly separates high and low amplitude zones in the study area. Contour spacing between two consecutive lines is 500. (Color figure online) 
under lying formation because reservoir properties have strong effect on acoustic impendence. Low amplitudes zones are also present in the map which may be associated with change in lithology or non-gas bearing zones. Lateral variations of amplitudes can be seen clearly on map which may be associated with the thickness of this gas reservoir. This attribute is more suitable to identify the changes in lithology with in the sequences.

\subsection{Average reflection strength}

Average reflection strength attribute represent the total energy strength of the trace and is independent of phase due to which it is more suitable to analyze the amplitude anomalies in detail. Reflection strength of each time sample is calculated as follow:

$$
\text { Reflection strength }=\sqrt{(\text { real trace })^{2}+(\text { quadrature trace })^{2}}
$$

Above formula shows that values of reflection strength is always positive. Keeping in mind its sensitivity with amplitudes anomalies this attribute was also extracted. Figure 9 shows the contours map of average reflection strength. Map clearly separates the high, moderate and low reflection zones. Moderate to high reflections may be associated with

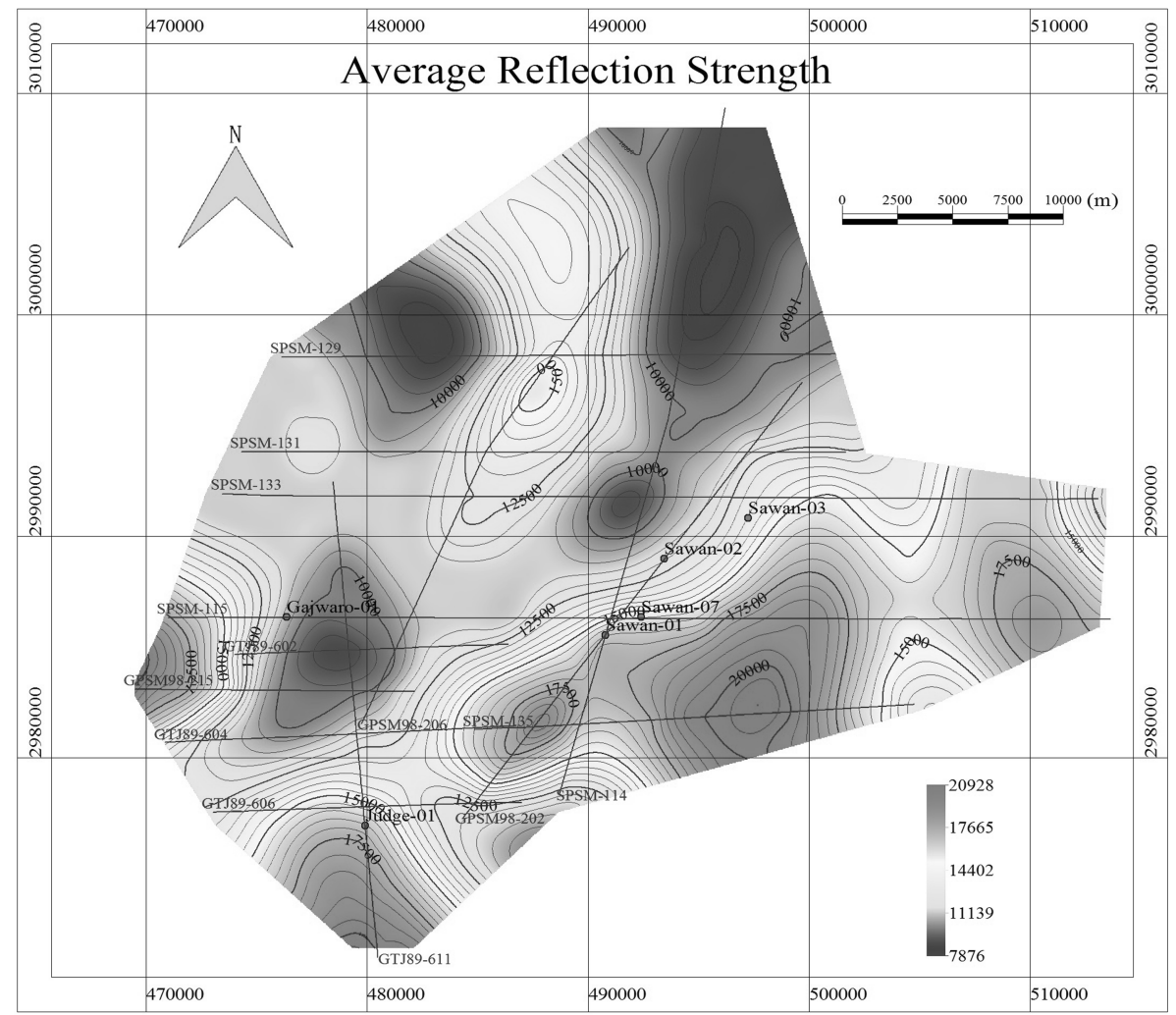

Fig. 9 Average reflection strength attribute map, red color represent to high average reflection strength while blue color represent to low average reflection strength. Contour spacing between two consecutive lines is 500. (Color figure online) 
major change in lithology, unconformities, stratigraphy as well as hydrocarbon accumulation. The high reflections also represents to gas filled pores or the composite response of thin beds due to tuning effect (Lynch and Lines 2004). Change in reflection strength in the map also provide information about the subtle change in lithology, thickness as well as extent of the reservoir. Map clearly shows that gas producing wells located in the moderate to strong reflection zones. Overall this map looks like the mirror image of RMS amplitude attribute map which support the results of above discussed amplitude statistics attributes.

\subsection{Energy half time}

Energy half time is the measure of the seismic energy distribution within the selected time window. Its value ranges from 0 to $100 \%$. Figure 10 shows the contour map of energy half time attribute. Attribute seems to be helpful in separating the different geologic features in the study area. Map clearly shows that a big low energy zone is located (in the middle of the map) between two high energy zones. Transgressive and regressive sequences can also be identified on the map on the basis of high energetic sand prone and low energetic shale prone

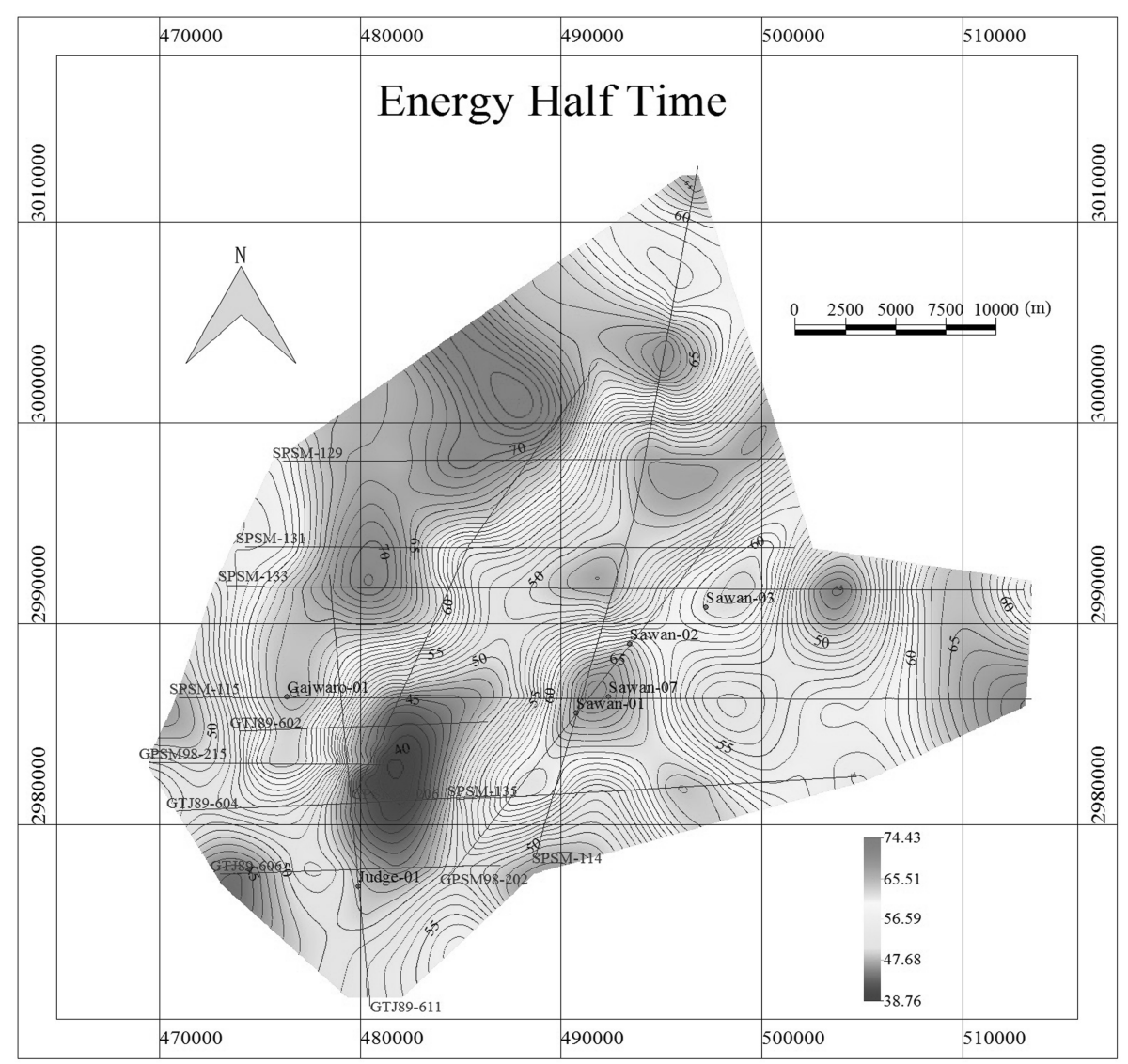

Fig. 10 Energy half time attribute distribution in study area. Contour spacing between two consecutive lines is $1 \%$. (Color figure online) 
zones. High energy zones indicate that sand facies overly shale facies whereas, low energy zone indicate that shale facies overlay sand facies. In the map the areas having almost near to $50 \%$ energy half time value indicate that in these areas sand shale facies are homogeneously distributed. Lateral changes in energy half time can be clearly seen on this map. These lateral changes in energy may be associated with variation in stratigraphy or amplitude anomalies. As gas bearing zones are often associated with amplitude anomalies (bright spots). This map clearly separates the lithological features like shale/sand distribution. Results of this attribute are more useful than RMS Amplitude, maximum peak amplitude and average reflection strength maps, as it separates the stratigraphic and amplitudes anomalies more clearly.

\subsection{Average instantaneous frequency}

Average instantaneous frequency attribute is measured by taking the derivative of instantaneous phase as a function of time (Taner et al. 1979; Barnes 1991; Cohen 1995). Figure 11 shows the contour map of average instantaneous frequency attribute. To simplify the map we have divided it into high and low frequency zones. Three low frequency zones are present in the map which covers more than half portion of the map. Low frequencies often associated with fracturing, change in lithology, hydrocarbon saturated reservoirs and

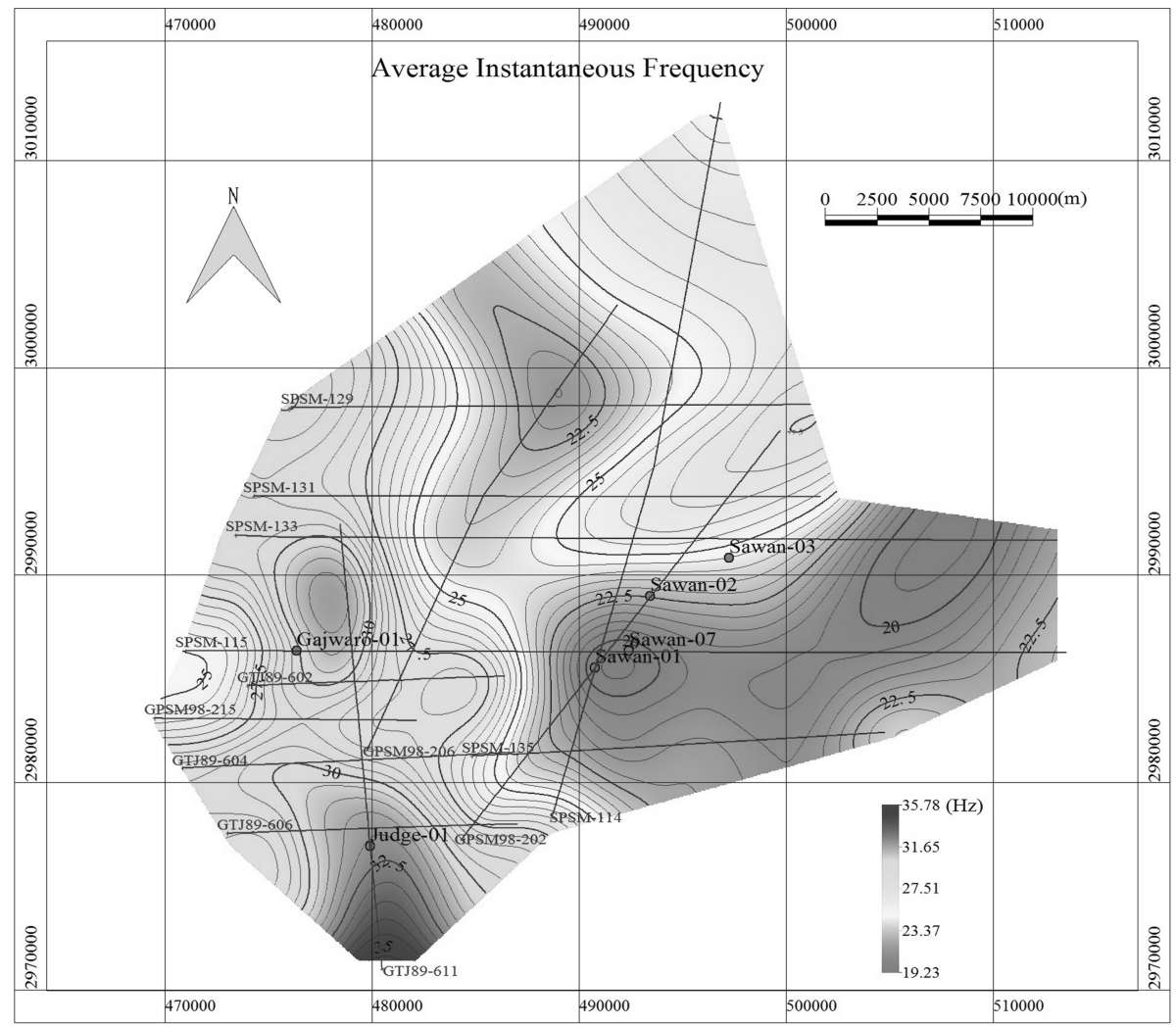

Fig. 11 Contour map of average instantaneous frequency clearly shows that gas producing wells are located in the low frequency zones whereas dry wells located in the high frequency zones. Contour spacing between two consecutive lines is $0.5 \mathrm{~Hz}$. (Color figure online) 
particularly with gas saturated sand. Whereas high frequency zones are associated with non-gas bearing zones and sharp interfaces which may exhibit to thin laminated shale (Taner et al. 1979). This attribute map clearly indicates that productive wells located in the very low frequency zone whereas, non-productive wells located in the high frequency zones. The high frequency zone in the vicinity of Gajwaro-01 well exhibits that this sand zone is highly interbedded with shale. Figure also shows that Sawan-01 and Sawan-07 wells are located in the lowest frequencies zone. These lowest frequencies correspond to the strongest gas absorption effects and thickest reservoir zones whereas, high frequency zones exhibits that reservoirs are thin in those particular places.

\subsection{Peak spectral frequency}

Peak spectral frequency is the measure of most substantial frequency component of the power spectrum. For more detailed and precise analysis peak spectral frequency attribute has been analyzed as this attribute provides more detailed and improved results than average instantaneous frequency. Figure 12 shows the contours map of peak spectral frequency attribute. This map more clearly indicates the subtle frequency trends associated with

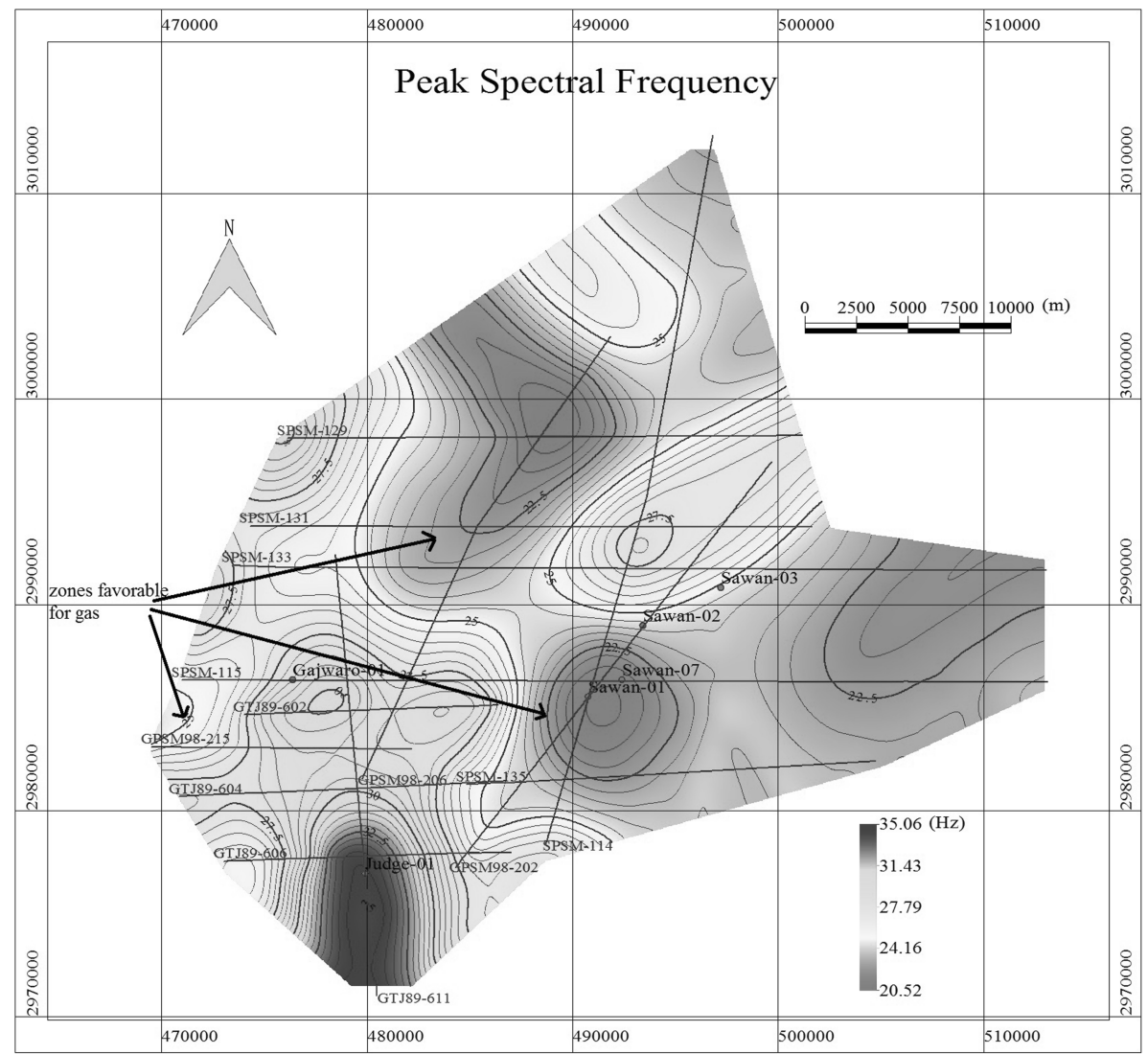

Fig. 12 Contour map of peak spectral frequency attribute. Red and yellow colors represent to low frequencies while green and blue colors represents to higher frequencies. Contour spacing between two consecutive lines is $0.5 \mathrm{~Hz}$. (Color figure online) 
lithological changes and gas bearing sand zones than Fig. 11. Low frequency zones cover the most part of the map. This map more clearly indicates the lateral variation in frequency, as wells having thicker gas reservoir are located in the very low frequency zone. One big high frequency zone is located in lower part (south) of map. High frequencies indicate that sand reservoir is thin and also include thin laminated shale which, makes these zones not favorable for gas accumulation. The location of non-productive gas wells (Gajwaro01 and Judge-01) in the high frequency zone confirms the reliability of the attribute results.

\subsection{Average instantaneous phase}

Average instantaneous phase describe the angle between the rotating vector and a real axis as a function of time. Its value ranges from +180 to $-180^{\circ}$. Attribute is useful to analyze the lateral bedding continuity, fluid content, pinchout, channel fans and depositional environments. Attribute is also helpful to distinguish the payable and non-able zones especially when the amplitude attributes are biased due to tuning effect (Bodine 1986; Chen and Sidney 1997). From Fig. 13 it is clearly seen a sharp variation in phase values which, indicate that bedding continuity and fluid content of sediments are changing

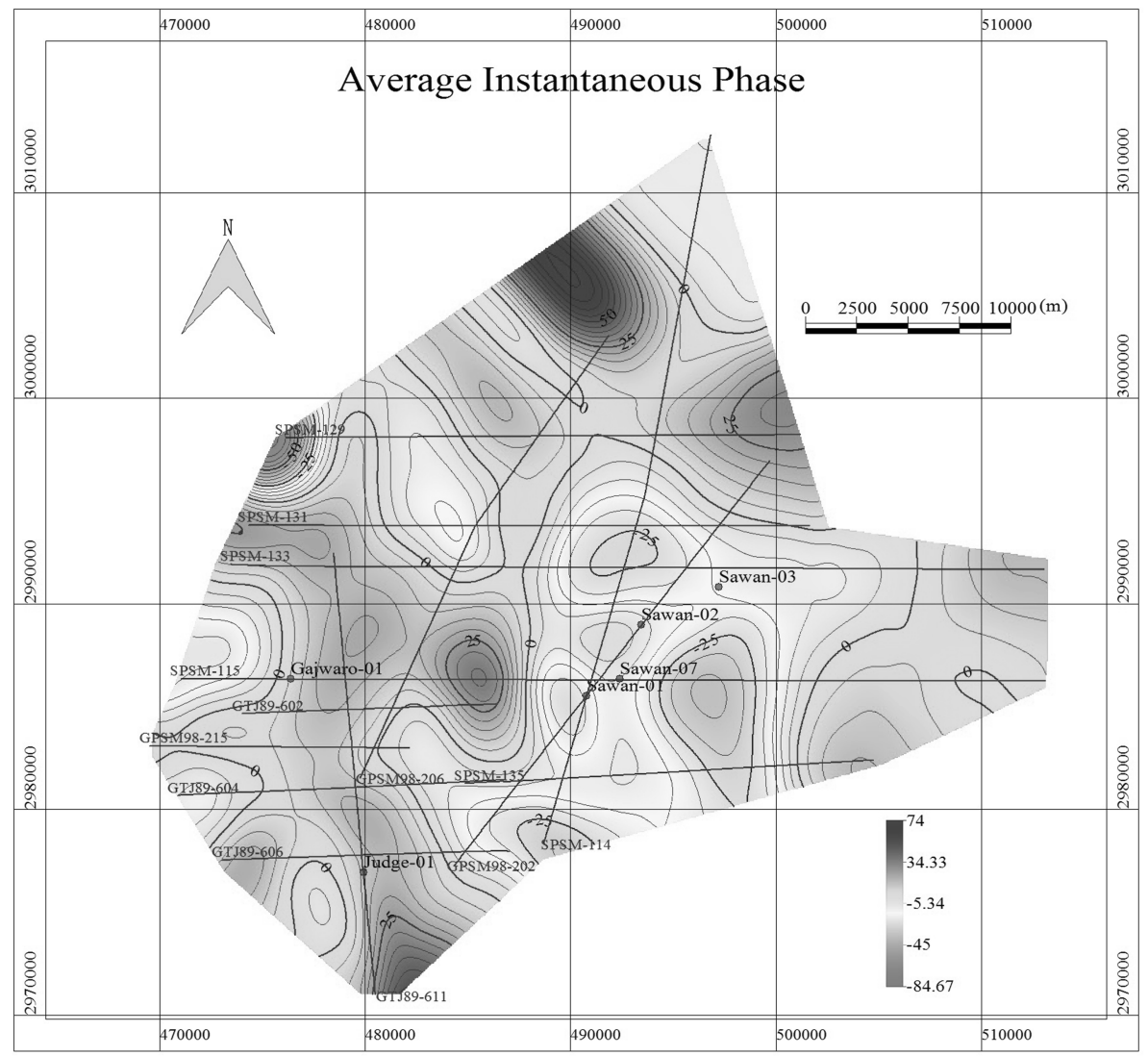

Fig. 13 Map of average instantaneous phase representing the lateral bedding continuity in the targeted zone. Contour spacing between two consecutive lines is $5^{\circ}$. (Color figure online) 
quickly. So, attributes results reveals that beds are not as continues as other attributes result indicate. The negative phase values in the map indicate that sands of these zones have good porosity and good sorting and favorable for gas. Judge-01 well is located in the positive phase zone which, mean this zone does not have good quality sand so, increase in amplitude values in this zone are due to tuning effect.

\subsection{Sweetness}

For more detailed analysis particularly at wells position sweetness attribute was extracted on the seismic sections. Sweetness is derived by dividing the reflection strength (instantaneous amplitude) by the square root of instantaneous frequency (Radovich and Oliveros 1998; Hart 2008). Mathematically it can be expressed as shown in Eq. 3.

$$
\text { Sweetness }=\frac{\operatorname{Ins}(A)}{\sqrt{\operatorname{Ins}(f)}}
$$

where Ins $(A)$ represents instantaneous amplitude (reflection strength) and Ins $(f)$ represents to instantaneous frequency. Attribute is useful to detect the channels, stratigraphic features and hydrocarbon reservoirs. Commonly, it is used to distinguish the sand bodies as the acoustic impedance contrast between sands and shales is relatively higher in the clastic environments (Hart 2008; Ahmad and Rowell 2012). Figure 14 represent to sweetness attribute of two seismic sections. Figure 14a represent to seismic line SPSM-115 and Fig. 14b represent to tie between two seismic lines (SPSM-115 and GTJ 89-611). In the map the high sweetness zones represent to cleaner and payable sand zones whereas, low sweetness zones are shale prone or these sands interbedded with shales. In the map three high sweetness areas can be clearly seen as marked by circles. The position of Sawan-07 well located in this high sweetness zone whereas, Judge-01 and Gajwaro-01 wells are located in the relatively low sweetness zones in the targeted window. But we can see a high sweetness zone in the vicinity of Gajwaro-01 well below this targeted window. This good quality sand zone seems to have potential for producing gas. Munir et al. (2011) also suggested that this zone (bright spot) have potential for gas if it is evaluated properly. The 3rd zone also seem to have good quality gas sand. Map of this attribute more clearly separate the productive and non-productive sand zones.

\subsection{Statistical analysis}

Lateral variations in above discussed seismic attributes maps provide a base for quantification analysis. As, seismic attributes also been proven useful for quantification analysis of reservoir properties. It is common practice to correlate the seismic attribute of interest with the petrophysical parameter extracted from wireline logs. Commonly regression, geostatistics and neural networks methods are used to predict the reservoir properties (Chambers and Yarus 2002). We used regression method to quantify the relationship between seismic attributes and petrophysical parameters. In the study area, Sawan-01, Sawan-02, Sawan-03 and Sawan-07 wells are productive with reservoir thickness 70, 37, 44, $67 \mathrm{~m}$ respectively. Analyzed seismic attributes were cross plotted against the thickness of gas reservoir (Fig. 15) as suggested by White (1991) that cross plotting is helpful for visual analysis. Visual analysis of these cross plots suggest that linear regression method can be useful to find the relationship between the plotted variables. (Barnes 2001) also suggested the same method for amplitude statistics attributes. So, linear regression method 


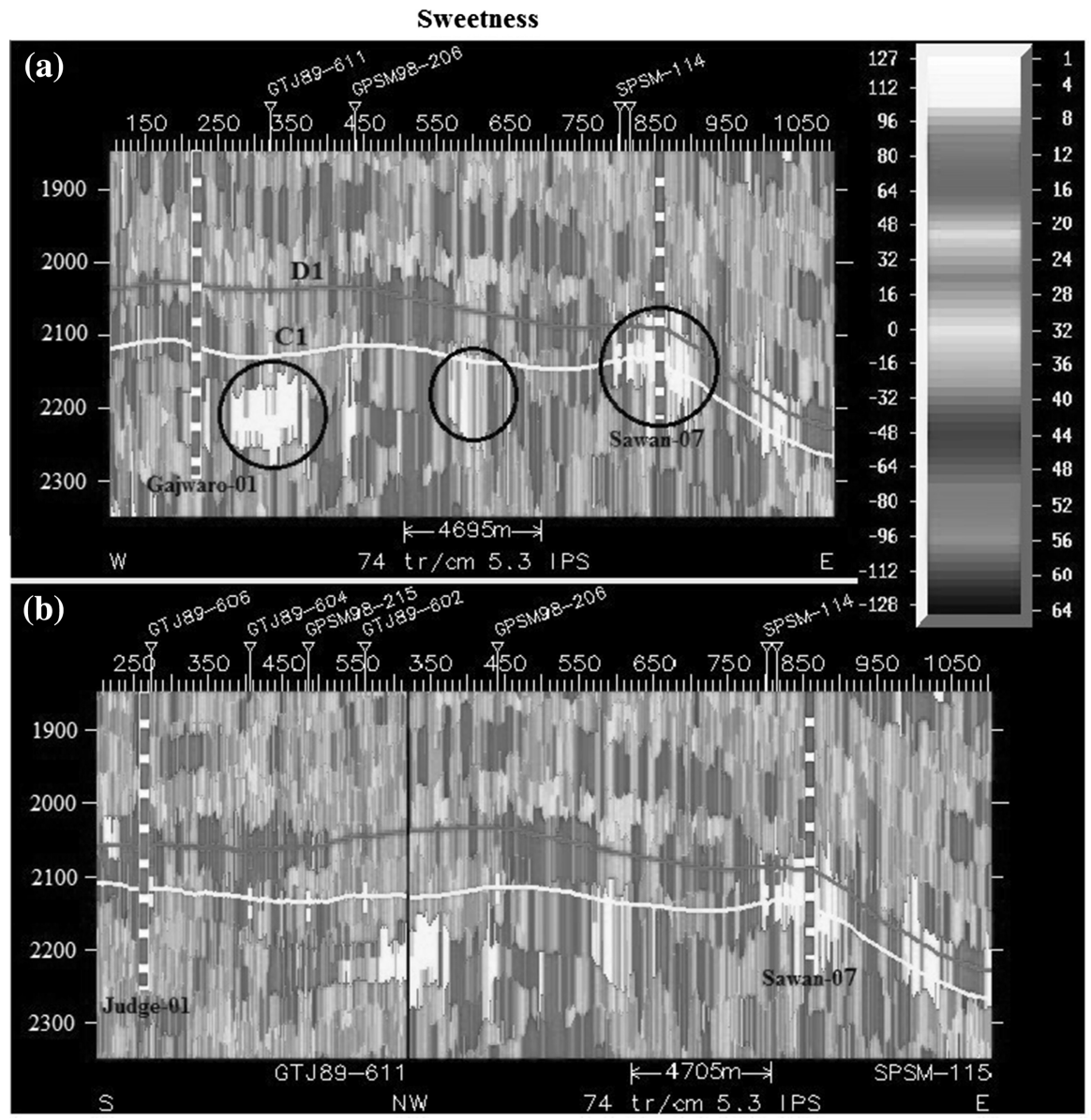

Fig. 14 Sweetness attribute extracted on the seismic sections showing three sweet spots as represented with black circles. (Color figure online)

is adopted to quantify the correlation strength of these plotted variables. Obtained correlation value $\left(\mathrm{R}^{2}\right)$ and equation of linear regression of each attribute is shown in Fig. 15. Mathematically, this linear regression equation can be generalized as

$$
Y=b X+c
$$

In Eq. 4, $X$ represent to thickness of gas reservoirs, $Y$ is seismic attribute value, $c$ is the slope intercept and $b$ is the slope of the line. Regression analysis (Fig. 15) clearly show that the scatter plots not only have good correlation but also follow the true physical relation trends, which provide a statistical support to our study. These trends also helpful to understand the physical rock properties of the surrounding area based on seismic response. Scatter plots of RMS amplitude, maximum peak amplitude, average reflection strength and energy half time attributes show linear increasing trend, which mean zones bearing high values of these attributes have thicker gas reservoirs. Whereas average instantaneous frequency, peak spectral frequency and average instantaneous phase attributes show 

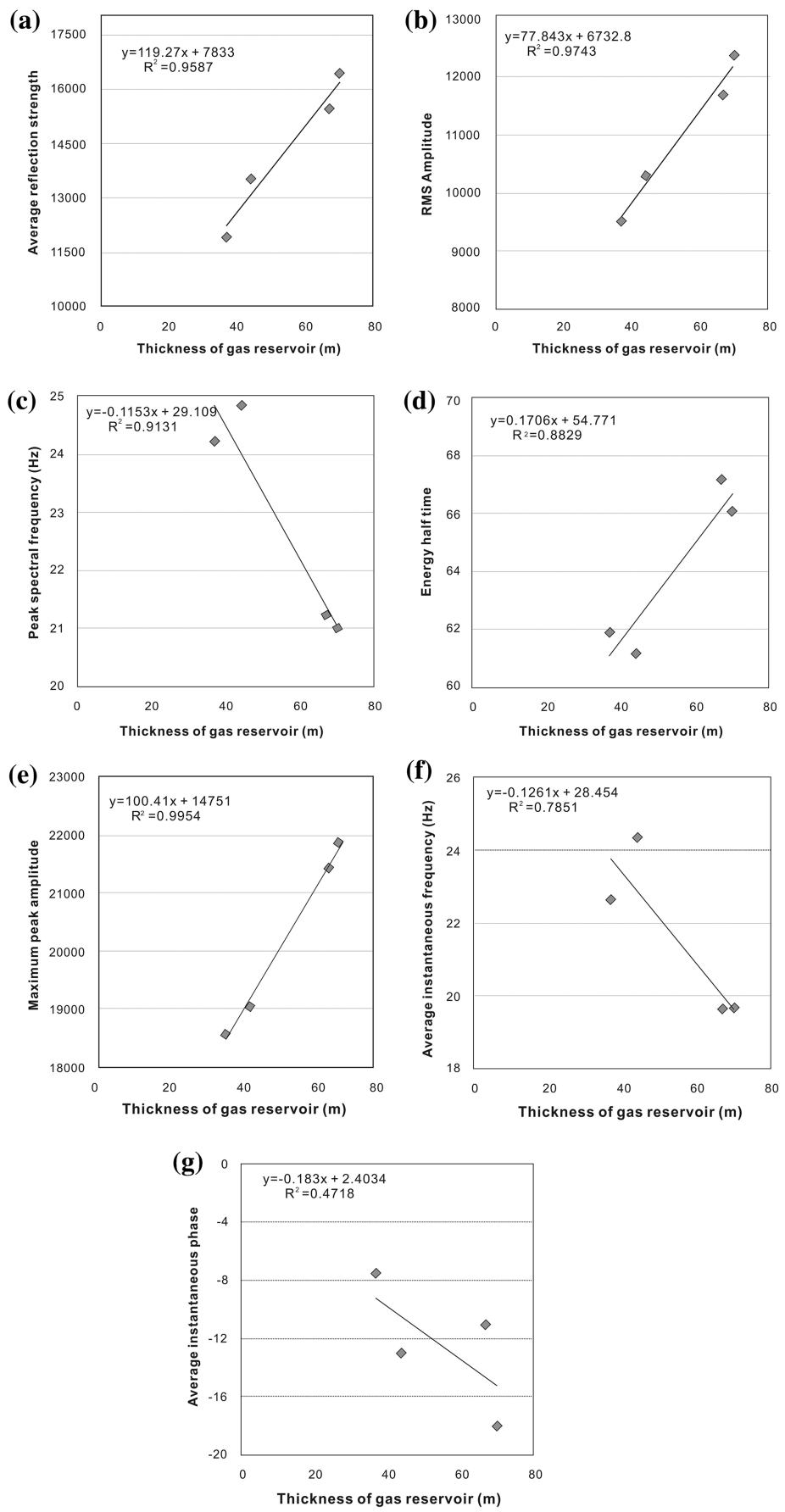

Fig. 15 Regression analysis, (a) average reflection strength versus thickness of gas reservoir, (b) RMS amplitude versus thickness of gas reservoir (c) peak spectral Frequency versus thickness of gas reservoir, (d) energy half time versus thickness of gas reservoir, (e) maximum peak amplitude versus thickness of gas reservoir, (f) average instantaneous frequency versus thickness of gas reservoir and (g) average instantaneous phase versus thickness of gas reservoir 
decreasing trends, which mean lower the value of attributes higher the thickness of gas reservoir. We have found that regression analysis seem to be useful for the quantification of reservoir thickness in the study area. However, average instantaneous phase does not show good correlation with the thickness of the gas layer as, this attribute is more suitable to detect the lateral variation.

\section{Discussion}

Seismic attributes analysis were performed to interpret the facies units within the targeted interval in terms of litho-fluid distribution and environments of deposition. The moderate to high values of amplitude attributes (Figs. 7, 8 and 9) represent to sand bodies and their direction. The location of producing wells (Sawan-01, 02, 03 and 07) in the moderate to high amplitude zone (Figs. 7, 8 and 9) indicate that this reservoir interval is composed of sandstones which, were deposited in the shoreface environments (Sahoo et al. 2014; Blanke 2013). The distribution of energy content (Fig. 10) indicate that gas producing sand was deposited in the regressive period whereas, non-productive sand/shale were deposited in the transgressive period. However, Judge-01 dry well also located in the high amplitude zone which, creates ambiguity. High values of amplitude attributes in this zone is due to tuning effect. As, the average instantaneous frequency, peak spectral frequency and phase attributes clearly indicate that this well is located in the high frequency zone with positive phase value (Figs. 11, 12 and 13). Very high frequency values in this zone indicate that reservoir interval is very thin and fall in the seismic resolution limit due to which, the reflections from the top and bottom of the reservoir interval go to constructive or destructive interference and causes to produce high amplitude event. These high values of frequencies also indicate that reservoir zone is highly interbedded with thin laminated shale layers whereas, lowest values indicates that gas bearing sand reservoir is more thick in this area. In frequency maps (Figs. 11, 12) contour of $25 \mathrm{~Hz}$ clearly draw a boundary between productive sand and non-productive sand/shale. The payable sands show low to moderate lateral continuity whereas, non-payable sands/shales show very less continuity (Fig. 13). To further analyze the lateral as well as vertical variation in the targeted interval, seismic attribute sweetness was extracted on the seismic sections as shown in Fig. 14. Gas producing well (Sawan-07) is located at the shelf edge deltas which hits sweet spot in the targeted zone (Fig. 14). This sweet spot is bounded by low sweetness zones. This particular location indicate that shoreface lowstand system tract gas producing sand was deposited on the distal shaly and silty sediment of the highstand system tract which, was sealed by transgressive shales and siltstones (Fig. 14). Whereas, Judge-01 and Gajwaro-01 wells are located in the relatively low sweetness zones and sand of these areas also seems to be in patches (not well connected). However, two sweet spots can be seen in Fig. 14 bounded by circles which, seem to be favorable for hydrocarbon potential.

\section{Conclusions}

Qualitative and quantitative analysis of seismic attributes have been proven helpful in delineating the gas bearing and non-gas bearing sand zones in the Sawan gas field of Pakistan. Average instantaneous frequency, peak spectral frequency, average instantaneous phase and sweetness attributes more clearly distinguish the gas bearing and non-gas 
bearing sand zones, as dry wells are located in the high frequency, positive phase and relatively in low sweetness zones whereas, gas producing wells are located in the low frequency, negative phase and high sweetness zones. RMS amplitude, maximum peak amplitude and average reflection strength attributes clearly mark the high and low values amplitudes zones, high value of these attributes indicate to sand saturated with gas. However, these high values of amplitude attributes near the Judge-01 well is due to tuning effect. Average instantaneous phase and sweetness attributes show that sands in the targeted zone have low to moderate connectivity. Sweetness attribute map show two more sweet spot indicated by black circles which, seem to be favorable for hydrocarbon potential. Energy half time attribute proven helpful to identify the transgressive and regressive sequences. So, we can conclude that the zones which, show high values of amplitude attributes, energy half time and sweetness, low frequency and negative phase values are favorable for gas.

Quantitative analysis show that discussed attributes have very good correlation value $\left(\mathrm{R}^{2}>0.78\right)$ except average instantaneous phase as it is more suitable to analyze the lateral variations. Amplitude attributes appear to be primary followed by peak spectral frequency, energy half time and average instantaneous frequency attributes and average instantaneous phase.

The applied method have some limitations it should be applied in the stable sedimentary facies zones as the lateral dramatic variation in amplitude causes big change in structure so method should not be applied in such areas. During the selection of top and bottom horizons the time window value should be kept in mind because large time window value will not produce good results.

Acknowledgments The authors are greatly thankful to Directorate General of Petroleum Concession (DGPC), Pakistan for the release of seismic and well data used in this study. We extend our grateful appreciation to National High-Tech R\&D Program of China (2013AA064201) for their financial support to this study. We also thankful to our lab mates (working at Geo-detection lab, China University of Geosciences, Beijing) for their support for the completion of this study.

\section{References}

Ahmad MN, Rowell P (2012) Application of spectral decomposition and seismic attributes to understand the structure and distribution of sand reservoirs within Tertiary rift basins of the Gulf of Thailand. Lead Edge 31:630-634

Ahmad N, Fink P, Sturrock S, Mahmood T, Ibrahim M (2004) Sequence stratigraphy as predictive tool in Lower Goru fairway, Lower Middle Indus Platform, Pakistan. PAPG-SPE ATC, pp 85-105

Badly ME (1985) Practical seismic interpretation. IHRDC Publishers, Boston, p 179

Barnes AE (1991) Instantaneous frequency and amplitude at the envelope peak of a constant-phase wavelet. Geophysics 56(7):1058-1060

Barnes AE (2001) Seismic attributes in your facies. CSEG Rec 09:41-47

Berger A, Gier S, Krois P (2009) Porosity-preserving chlorite cements in shallow -marine volcaniclastic sandstones: evidence of the sawan gas field Pakistan. AAPG Bull 93(5):595-615

Blanke SJ (2013) Saucer sills of the offshore Canterbury Basin. Advantage NZ Petroleum Conference, Auckland

Bodine JH (1984) Waveform analysis with seismic attributes. SEG 54th Annual International Meeting, Atlanta

Bodine JH (1986) Waveform analysis with seismic attributes. Oil Gas J 84(24):59-63

Chambers RL, Yarus JM (2002) Quantitative use of seismic attributes for reservoir characterization. CSEG Rec 06:15-25

Chen Q, Sidney S (1997) Seismic attribute technology for reservoir forecasting and monitoring. Lead Edge $16: 445-456$ 
Chopra S, Marfurt KJ (2005) Attribute review paper-75th Ann of SEG: Draft 3. 15 Mar 2005, p 51

Chung HM, Lawton DC (1995) Amplitude responses of thin beds: sinusoidal approximation versus Ricker approximation. Geophysics 60(3):223-230

Cohen L (1995) Time-frequency analysis. Prentice-Hall Signal Processing Series, New York

Dalley RM, Gevers ECA, Stampfli GM, Davies DJ, Gastaldi CN, Ruijtenberg PA, Vermeer GJO (1989) Dip and azimuth displays for 3-D seismic interpretation. First Break 07(03):86-95

Dobrin MB, Savit CH (1988) Introduction to geophysical prospecting. McGraw Hill Book Co., Inc., New York

El-Mowafy H, Marfurt K (2008) Structural interpretation of the middle frio formation using 3D seismic and well logs: an example from the gulf coast of the United State. Lead Edge 27(7):840-848

Fu D, Sullivan EC, Marfurt KJ (2006) Rock-property and seismic attribute analysis of a chert reservoir in the Devonian Thirty-one Formation, west Texas, USA. Geophysics 71:B151-B158

Gholami R, Moradzadeh A, Rasouli V, Hanachi J (2014) Shear wave velocity prediction using seismic attributes and well log data. Acta Geophys 62(4):818-848. doi:10.2478/s11600-013-0200-7

Hart BS (2008) Channel detection in 3-D seismic data using sweetness. AAPG Bull 92:733-742. doi:10. 1306/02050807127

Horkowitz KO, Davis DR (1996) Seismic delineation of thin sandstone reservoirs in a shale-rich sequence using instantaneous frequency and reflection amplitude attributes from 3-D data, Texas Gulf coast. AAPG studies in Geology No. 42 and SEG geophysical Development series No. 5

Iqbal MWA, Shah SMI (1980) A guide to the stratigraphy of Pakistan, Geological Survey of Pakistan Records. Geol Surv Pak Quetta 53:34

Kadri IB (1995) Petroleum geology of Pakistan. Graphic Publishers, Karachi, pp 93-108

Khalid P, Ghazi S (2013) Discrimination of fizz water and gas reservoir by AVO analysis: a modified approach. Acta Geod Geophys 48:347-361. doi:10.1007/s40328-013-0023-7

Khalid P, Qayyum F, Yasin Q (2014a) Data driven sequence stratigraphy of the cretaceous depositional system, Punjab Platform, Pakistan. Surv Geophys 35:1065-1088. doi:10.1007/s10712-014-9289-8

Khalid P, Broseta D, Nichita DV, Blanco J (2014b) A modified rock physics model for analysis of seismic signatures of low gas-saturated rocks. Arab J Geosci 07:3281-3295. doi:10.1007/s12517-013-1024-0

Krois P, Mahmood T, Milan G (1998) Miano field, Pakistan a case history of model driven exporation. Proceedings of the Pakistan Petroleum Convention, Pakistan Association of Petroleum Geologists Islamabad: pp 111-131

Løseth H, Gading M, Wensaas L (2009) Hydrocarbon leakage interpreted on seismic data. Mar. Petrol Geol 26(7):1304-1319. doi:10.1016/j.marpetgeo.2008.09.008

Lynch S, Lines L (2004) Combined attributes displays. 72nd Annual International Meeting, SEG, expanded abstracts, pp 1953-1956

Marfurt KJ, Kirlin RL (2001) Narrow-band spectral analysis and thin-bed tuning. Geophysics 4:1274-1283

Marfurt KJ, Kirlin RL, Farmer SL, Bahorich MS (1998) 3-D seismic attributes using a semblance-based coherency algorithm. Geophysics 63:1150-1165

McPhee CA, Enzendorfer CK (2004) Sand management solutions for high-rate gas wells, sawan field. SPE, Sindh (86535)

Munir K, Iqbal MA, Farid A, Shabih SM (2011) Mapping the productive sands of Lower Goru Formation by using seismic stratigraphy and rock physical studies in Sawan area, southern Pakistan: a case study. J Petrol Explor Prod Technol 1:33-42. doi:10.1007/s13202-011-0003-9

Radovich BJ, Oliveros RB (1998) 3-D sequence interpretation of seismic instantaneous attributes from the Gorgon field. Lead Edge 17:1286-1293. doi:10.1190/1.1438125

Raef AE, Mattern F, Philip C, Totten MW (2015) 3D seismic attributes and well-log facies analysis for prospect identification and evaluation: interpreted palaeoshoreline implications, Weirman Field, KS, USA. J Petrol Sci Eng. doi:10.1016/j.petrol.2015.04.028

Rana S, Burley S, Chowdhury S (2006) The application of hierarchical seismic attribute combination to high precision infill well planning in the South Tapti Field, Offshore Western India. GEOHORIZONS. J Soc Pet Geophy 11:32-37

Robertson JD, Nogami HH (1984) Complex seismic trace analysis of thin beds. Geophysics 49(4):344-352. doi:10.1190/1.1441670

Sahoo TR, Browne GH, Hill MG (2014) Seismic attribute analysis and depositional elements in the Canterbury Basin. GNS Science, Lower Hutt

Sonneland L, Barkved O, Olsen M, Snyder G (1989) Application of seismic wave-field attributes in reservoir characterization: 59th Annual International Meeting, Society of Exploration Geophysicists, p 813

Taner MT (2001) Seismic attributes, CSEG Recorder, pp 48-56, September Issue

Taner MT, Koehler F, Sheriff RE (1979) Complex seismic trace analysis. Geophysics 44(6):1041-1063 
Taner MT, Schuelke JS, Doherty RO, Baysal E (1994) Seismic attributes revisited, SEG technical program, expanded abstracts. pp 1104-1106, doi: 10.1190/1.1822709

Wandrey CJ, Law BE, Shah HA (2004) Sembar goru/Ghazij composite total petroleum system Indus and sulaiman-kirthar geologic provinces Pakistan and India. US Geological Survey, USA; Geol Surv Bull 2208-C

Wang Z, Yin YC, Fan T, Lei X (2012) Seismic geomorphology of a channel reservoir in lower Minghuazhen Formation, Laizhouwan sub-basin, China. Geophysics 77(4):187-195. doi:10.1190/geo20110209.1

White RE (1991) Properties of instantaneous seismic attributes. Lead Edge 10(7):26-32

Widess MB (1973) How thin is a thin bed. Geophysics 38:1176-1180

Ye TR, Su JY, Liu XY (2008) Application of seismic frequency division interpretation technology in predicting continental sandstone reservoir in the west of Sichuan province. Geophys Prospect Petrol 47(1):72-76

Yushuang Hu, Zhu Simiao (2013) Predict channel sand body distribution characteristics of south eighth district based on RMS amplitude attributes \& frequency division. Adv Mater Res 734:404-407 